\title{
Причины младенческой смертности по Нерюнгринскому району Республики Саха (Якутия)
}

\author{
Тайшина С.С., студентка, \\ ГБПОУ РС (Я) «Нерюнгринский медицинский колледж», \\ 2. Нерюнгри, \\ E-mail: nermedu@mail.ru
}

Научный руководитель: преподаватель Бородкина Л.Х.

Младенческая смертность - один из демографических факторов, наиболее наглядно отражающих уровень развития страны и происходящие в ней экономические и социальные изменения. В XX веке уровень младенческой смертности в России снизился почти в 20 раз. Изменилась и ее доля в уровне общей смертности. Но за этими положительными достижениями скрыты тенденции, вызывающие серьезную озабоченность. Рассмотрим динамику и особенности этого процесса.

Цель работы: определение причин младенческой смертности в Нерюнгринском районе РС (Я) за последние 3 года.

Как и другие демографические показатели, младенческая смертность может выражаться как в абсолютных, так и в относительных терминах. Относительный показатель, или коэффициент младенческой смертности, выражается обычно в промилле (\%о) и обозначает количество детей, умерших в возрасте до 1 года на 1000 новорожденных за один год; гораздо реже используются коэффициенты в расчёте на 100 или 10000 новорожденных [1].

Факторы риска младенческой смертности: возраст ребенка; негармоничное физическое развитие женщин; акселерация плода; позднее вступление в брак; первые роды в возрасте от 30 лет; загрязнение окружающей среды тяжелыми металлами и радиоактивными веществами; дефекты в медицинском наблюдении за беременными; низкий уровень состояния здоровья родителей; нежелание иметь ребенка; брачное состояние; образ жизни семьи; ранний перевод на искусственное вскармливание; несоблюдение правил ухода и закаливания; наличие у детей фоновых заболеваний (рахит, гипертрофия и т.д.).

Для получения статистических данных показателей младенческой смертности по Нерюнгринскому району за 2014-2016 годы мы обратились в детскую консультацию Нерюнгринской ЦРБ.

За 2016 г. отмечается снижение общей заболеваемости детей 1 года жизни по сравнению с 2014 годом на 1019 случаев (389\%о) в основном за счет прочих заболеваний (923 случая) и болезней органов пищеварения (227 случаев). За этот же период болезни нервной системы уменьшились на 95 случаев (58,3\%). Болезни органов дыхания в 2016 г. увеличились на 168 случаев (555,2\%) по сравнению с 2014 г. Также отмечается рост отдельных состояний, возникающих в перинатальном периоде, на 58 случаев (204,3\%о). Результаты анализа показателей заболеваемости детей представлены на рис. 1-2 и в табл. 1.

Среди заболеваний детей первого года жизни все 3 года на I месте - болезни органов дыхания, на II месте - болезни нервной системы, на III месте - отдельные 
состояния, возникающие в перинатальном периоде и на IV месте - болезни органов пищеварения.

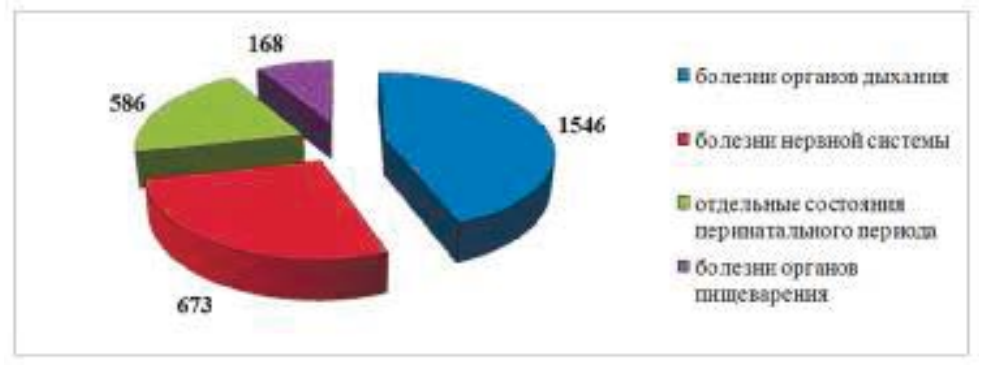

Рис. 1. Структура заболеваемости детей до 1 года за 2016 г.

Таблица 1

Структура заболеваемости детей до 14 лет за 2014-2016 гг.

\begin{tabular}{|l|c|c|c|c|c|c|}
\hline \multirow{2}{*}{ Виды заболеваний } & \multicolumn{2}{|c|}{2014 г. } & \multicolumn{2}{c|}{2015 г. } & \multicolumn{2}{c|}{2016 г. } \\
\cline { 2 - 7 } & Абс. & $\%$ & Абс. & $\%$ & Абс. & $\%$ \\
\hline $\begin{array}{l}\text { Заболеваемость детей до14 } \\
\text { лет }\end{array}$ & $\begin{array}{c}47777 \\
(3303,6 \%)\end{array}$ & - & $\begin{array}{c}50391 \\
(3573,8 \% \text { o }\end{array}$ & - & $\begin{array}{c}43466 \\
(3022,8 \%)\end{array}$ & - \\
\hline $\begin{array}{l}\text { В т.ч. болезни органов } \\
\text { дыхания }\end{array}$ & 30842 & 64,5 & 30620 & 60,7 & 26488 & 60,9 \\
\hline Болезни нервной системы & 3316 & 6,9 & 4185 & 8,3 & 3167 & 7,2 \\
\hline $\begin{array}{l}\text { Болезни органов } \\
\text { пищеварения }\end{array}$ & 1887 & 3,9 & 2279 & 4,5 & 2689 & 6,1 \\
\hline $\begin{array}{l}\text { Болезни кожи и подкожной } \\
\text { клетчатки }\end{array}$ & 2041 & 4,2 & 2092 & 4,1 & 1886 & 4,3 \\
\hline Прочие & 9691 & - & 11215 & - & 9236 & - \\
\hline
\end{tabular}

За 2016 г. отмечается снижение общей заболеваемости детей до 14 лет по сравнению с 2014 годом на 4311 случаев (280,8\%о) в основном за счет болезней органов дыхания (4 354 случая - 9,1\%) и прочих заболеваний (455 случая - 4,7\%). Отмечается заметный рост болезней органов пищеварения в 2016 году - на 802 случая (42,5\%). Незначительно уменьшились болезни кожи и подкожной клетчатки - 155 случаев (7,6\%) и болезни нервной системы - на 149 случаев (4,5\%).

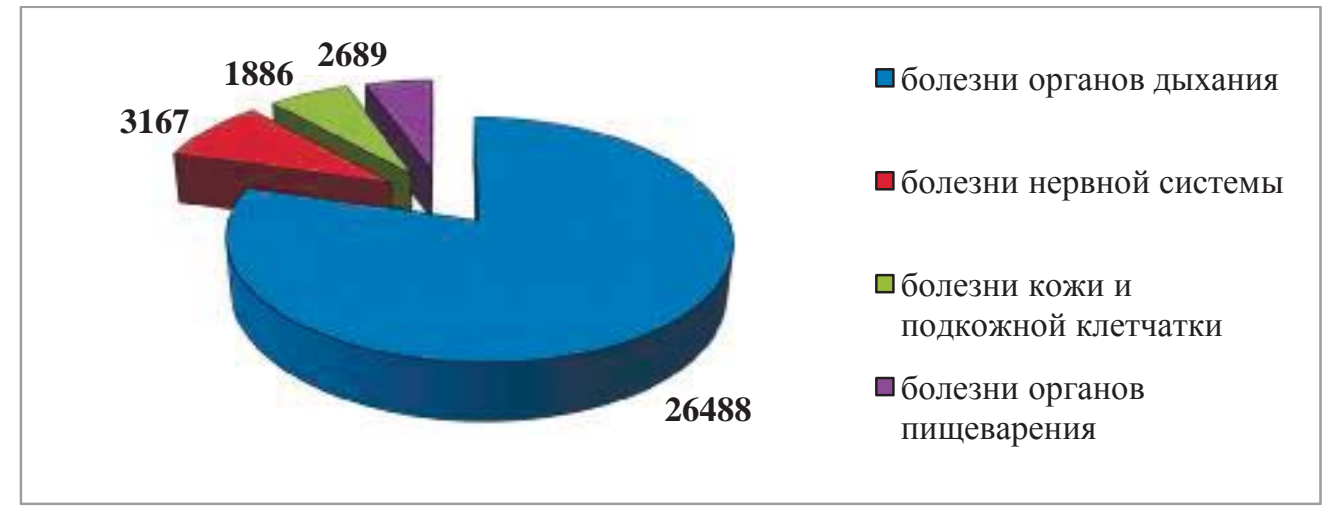

Рис. 2. Структура заболеваемости детей до 14 лет за 2016 г.

На I месте все 3 года - болезни органов дыхания, на II месте - болезни нервной системы, на III месте - болезни органов пищеварения (за исключением 2014 г.), на IV месте - болезни кожи и подкожной клетчатки. 
Ниже представлен анализ показателей рождаемости и младенческой смертности детей в Нерюнгринском райое РС (Я) за последние 3 года (табл. 2, рис. 3-9).

Таблица 2

Рождаемость по Нерюнгринскому району РС (Я) за 2014 - 2016 г.г.

\begin{tabular}{|l|c|c|c|c|c|c|}
\hline \multirow{2}{*}{ Родилось } & \multicolumn{2}{|c|}{2014} & \multicolumn{2}{c|}{2015} & \multicolumn{2}{c|}{2016} \\
\cline { 2 - 7 } & Абс. & \%о & Абс. & \%о & Абс. & \%о \\
\hline район & 968 & 12,2 & 947 & 12,06 & 816 & 10,7 \\
\hline город & 953 & - & 934 & - & 800 & - \\
\hline село & 15 & - & 13 & - & 16 & - \\
\hline
\end{tabular}

За последние 3 года отмечается тенденция к снижению рождаемости по Нерюнгринскому району РС (Я). В 2016 году родилось на 152 ребенка меньше, чем в 2014 году, т.е. на 15,7\%. Рождаемость снизилась на 1,5\% (12,3 \%).

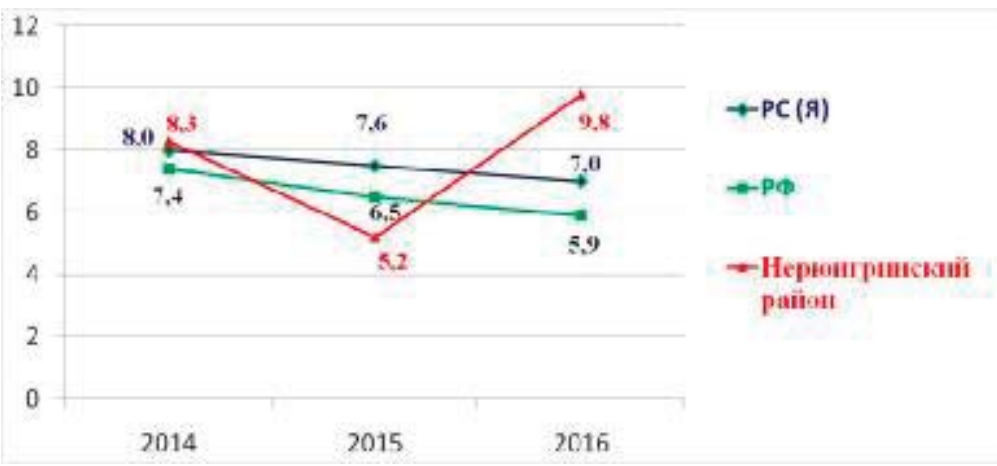

Рис. 3. Младенческая смертность за 2014-2016 гг. (на 1000 родившихся живыми) в сравнении с РС (Я) и РФ

Вывод: коэффициент младенческой смертности в Нерюнгринском районе РС (Я) за последние 3 года нестабилен. Самый низкий показатель отмечался в 2015 году 5,2\%, что ниже показателей младенческой смертности по РС (Я) в 1,5 раза и РФ в 1,3 раза. Но в 2016 году отмечается рост младенческой смертности до 9,8\%о, т.е. в 1,9 раза по сравнению с 2015 годом; в 2014 и 2016 годах выше, чем по РС (Я) и РФ.

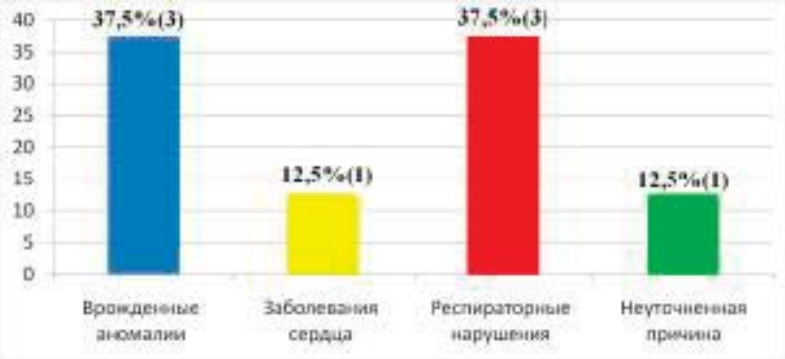

Рис. 4. Структура младенческой смертности за 2014 год, \%

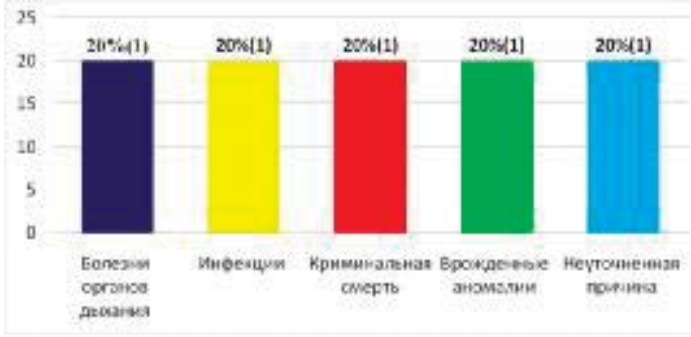

Рис. 5. Структура младенческой смертности за 2015 год, \%

В структуре младенческой смертности в 2014 году преобладают врожденные аномалии и респираторные нарушения - по 37,5\% (по 3 случая каждого). В 2015 году отмечались по 1 случаю смерти детей в возрасте до 1 года от болезни органов дыхания, инфекции, врожденной аномалии, криминальной смерти и неуточненной причины (по $20 \%)$. 


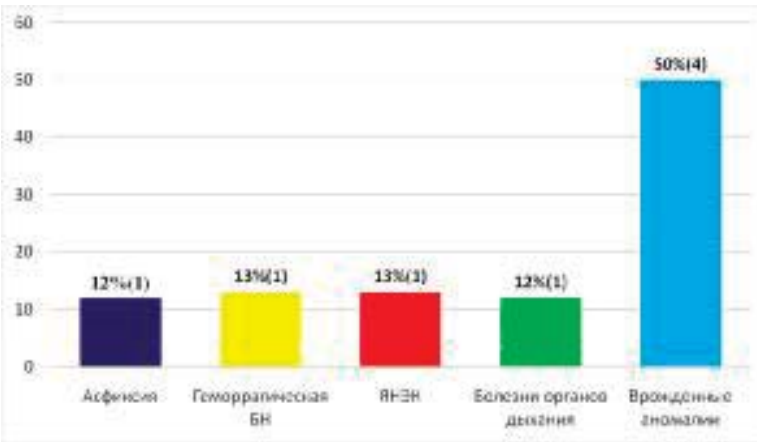

Рис. 6. Структура младенческой смертности от причин за 2016 год, \%

В структуре младенческой смертности за 2016 год 50\% (4 случая из 8) занимают врожденные аномалии и по 1 случаю (по 12,5\%) болезнь органов дыхания, асфиксия, геморрагическая болезнь новорожденного и язвенно-некротический энтероколит.

В зависимости от числа дней, прожитых детьми, умершими на 1-м году жизни, рассчитываются следующие специальные коэффициенты младенческой смертности: ранняя неонатальная смертность (смертность детей в возрасте 0-6 суток, т.е. в первые 168 ч жизни); поздняя неонатальная смертность (смертность детей в возрасте 7-28 суток жизни); неонатальная смертность (смертность детей в первые 28 суток жизни); постнеонатальная смертность (смертность детей в возрасте с 29-го дня жизни до 1 года).

Таблица 3

Показатели младенческой смертности по Нерюнгринскому району за 3 года в зависимости от числа прожитых дней

\begin{tabular}{|l|c|c|c|}
\hline $\begin{array}{l}\text { Показатели младенческой } \\
\text { смертности }\end{array}$ & 2014 & 2015 & 2016 \\
\hline Умерло до 1 года: & 8 & 5 & $2(25 \%)$ \\
\hline $\begin{array}{l}\text { В том числе: } \\
\text { от до 6 дней (ранняя } \\
\text { неонатальная) }\end{array}$ & $3(37,5 \%)$ & - & $2(25 \%)$ \\
\hline $\begin{array}{l}\text { от до 28 дней (поздняя } \\
\text { неонатальная) }\end{array}$ & $4(50 \%)$ & $1(20 \%)$ & $4(50 \%)$ \\
\hline $\begin{array}{l}\text { от } 28 \text { дней до 1 года } \\
\text { (постнатальная) }\end{array}$ & $1(12,5 \%)$ & $4(80 \%)$ & 9,8 \\
\hline Младенческая смертность (\%) & 8,3 & 5,2 & \\
\hline
\end{tabular}

Вывод: в 2014 г. 7 случаев младенческой смерти из 8 (т.е. 87,5 \%) приходится на неонатальный период. В 2015 г. большая часть смертей произошла в постнатальном периоде, а в 2016 г. по 50\% случаев в неонатальном и постнатальном периоде.

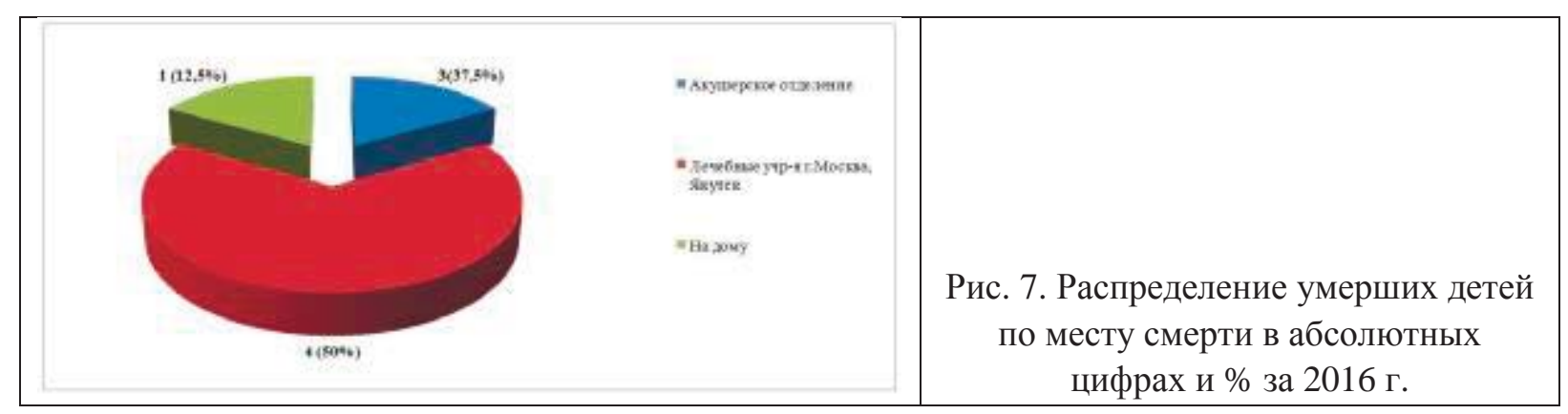


Распределение умерших детей по месту смерти за 2016 г. показывает, что 7 случаев смерти (87,5\%) произошло в лечебных учреждениях (акушерское отделение Нерюнгринской ЦРБ (37,5\%), лечебные учреждения г. Москвы и г. Якутска (50\%)) и 1 случай $(12,5 \%)$ на дому.

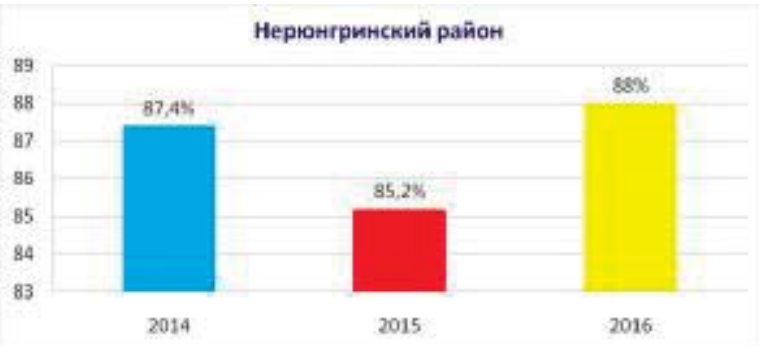

Рис. 8. Ранняя явка беременных на учет (до 12 недель)

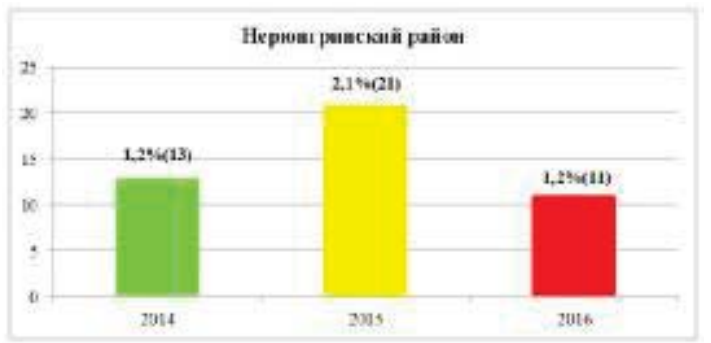

Рис. 9. Поздние явки беременных на учет (после 28 недель)

Учитывая показатели младенческой смертности по Нерюнгринскому району, мы решили изучить, какой процент беременных женщин встает на учет в женской консультации в ранние сроки беременности, т.е. до 12 недель. Оказалось, что явка беременных на ранних сроках высокая и составляет за последние 3 года от 85,2\% до 88\% от всех беременных. Позднее взятие беременных женщин на учет в женской консультации по Нерюнгринскому району составило от 1,2\% (в 2014 г. и 2016 г.) до $2,1 \%$ в 2015 г.

В настоящее время эксперты многих стран могут выделить три главные причины неонатальной смертности: недоношенность, врожденные пороки развития и асфиксия. В развивающихся странах неонатальная смертность в большинстве случаев является результатом инфекций (тяжелые формы сепсиса, столбняк, пневмония, диарея), а в развитых странах большой процент неонатальной смертности приходится на врожденные аномалии и пороки развития (чаще пороки сердечнососудистой и нервной систем).

Показатели младенческой смертности за 2014 и 2016 годы по Нерюнгринскому району выше, чем по Республике Саха (Якутия) и Российской Федерации, и чаще отмечалась среди детей в возрасте от 0 до 28 дней (неонатальный период) и реже в возрасте от 28 дней до 1 года (в 2015 г.). В 2014 г. и в 2016 г. большой процент среди причин младенческой смертности по Нерюнгринскому району составляют врожденные пороки развития $(37,5$ \% и 50 \%) и в эти же годы отмечаются более высокие показатели младенческой смертности (8,3\%о и 9,8\%). Показатели младенческой смертности в Нерюнгринском районе за последние 3 года дали такие же результаты, так как в 2014 и 2016 гг. также отмечается большой процент врожденных пороков развития.

Несмотря на то, что проводится целенаправленная работа по улучшению этих показателей, коэффициент младенческой смертности довольно высокий по Нерюнгринскому району: при ранней постановке беременной на учет до 12 недель ей выплачивается дополнительное пособие. За последние 3 года больший процент ранней явки на учет по беременности отмечается в 2016 г. - 88 \%; проводятся ультразвуковые исследования, которые могут выявить пороки развития на ранних сроках беременности; ведется профилактическая работа, направленная на сохранение женского здоровья и пропаганду здорового образа жизни для разной категории: беременных, молодежи, подростков. 
Учитывая нестабильный коэффициент младенческой смертности за последние 3 года, необходимо улучшить материально-техническую базу женской консультации для повышения выявляемости пороков развития в ранние сроки беременности, усилить санитарно-просветительную работу по планированию семьи, о необходимости ранней явки на учет при наступлении беременности, по пропаганде здорового образа жизни среди населения в целом и особенно - среди молодежи.

Список литературы:

1. Баранов А.А. Смертность детского населения в России (тенденции, причины и пути снижения): монография / А.А. Баранов, В.Ю. Альбицкий. - М.: Изд-во Союза педиатров России, 2009. - 387 с.

2. Дубровина Е.В. Резервы снижения младенческой смертности в России / Е.В. Дубровина // Вопросы современной педиатрии. - 2006. - № 6. - Т. 5. - С. 8-12.

3. Интернет-сайт Министерства здравоохранения Республики Саха (Якутия).

4. Медовиков П.С. Причины детской смертности. - СПб., 2004.

5. Методическое указание Минздрава России № 98/66 «Методика анализа младенческой смертности». - М., 2005. - 10 с

6. Перекатова М. Младенческая смертность: причины, показатели, формула и коэффициент [Электронный ресурс]. - Режим доступа: http://fb.ru/article/256251/ mladencheskaya-smertnost-prichinyi-pokazateli-formula-i-koeffitsient.

\title{
Ручейники - биологические индикаторы водоемов
}

\author{
Шампур К., \\ обучающийся МБУДО «ЦРТДиЮ», \\ 2. Нерюнгри
}

Научный руководитель: Проценко В.Н.

Данная исследовательская работа представляет практические материалы по выявлению загрязненности водных экосистем рек Нерюнгринского района на основе методики исследования макрозообентоса, делая акцент на преобладание амфибиотического вида ручейников.

Ранее определение видового состава беспозвоночных реки Чульман проводились кандидатом биологических наук Инной Вячеславовной Резник в летний период 2003 года. В 2010 году группа ученых (Т.М. Тиунова, В.А. Тесленко, М.А. Макарченко, С.Е. Сиротский) обследовала водотоки бассейна реки Тимптон и выяснила, что ручейники преобладали в реках Иенгра, Холодникан и Чульман, хирономиды - в реках Тимптон, Иенгра и Горбыллаах.

С 2010 года исследования фауны беспозвоночных не проводились. Поэтому новизна предлагаемой исследовательской работы заключается в собранных пробах ручейников в новом десятилетии и представляет собой материал для проведения мониторинговых работ.

Теоретическая и практическая значимость. Данные о видовом составе ручейников рек Чульман, Горбыллах, Улахан Нахот важны как исходные материалы 